NASA Technical Memorandum 4730

\title{
Development of a Real-Time Transport Performance Optimization Methodology
}

Glenn Gilyard

January 1996

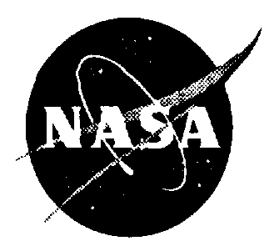


1 
NASA Technical Memorandum 4730

\section{Development of a Real-Time Transport Performance Optimization Methodology}

Glenn Gilyard

Dryden Flight Research Center

Edwards, California

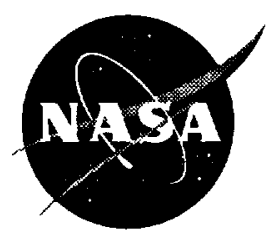

National Aeronautics and

Space Administration

Office of Management

Scientific and Technical

Information Program

1996 



\title{
DEVELOPMENT OF A REAL-TIME TRANSPORT PERFORMANCE OPTIMIZATION METHODOLOGY
}

\author{
Glenn Gilyard* \\ NASA Dryden Flight Research Center \\ Edwards, California
}

\begin{abstract}
The practical application of real-time performance optimization is addressed (using a wide-body transport simulation) based on real-time measurements and calculation of incremental drag from forced response maneuvers. Various controller combinations can be envisioned although this study used symmetric outboard aileron and stabilizer. The approach is based on navigation instrumentation and other measurements found on state-of-the-art transports. This information is used to calculate winds and angle of attack. Thrust is estimated from a representative engine model as a function of measured variables. The lift and drag equations are then used to calculate lift and drag coefficients. An expression for drag coefficient, which is a function of parasite drag, induced drag, and aileron drag, is solved from forced excitation response data. Estimates of the parasite drag, curvature of the aileron drag variation, and minimum drag aileron position are produced. Minimum drag is then obtained by repositioning the symmetric aileron. Simulation results are also presented which evaluate the affects of measurement bias and resolution.

\begin{tabular}{|c|c|}
\hline & Nomenclature \\
\hline APO & adaptive performance optimization \\
\hline ACEE & aircraft energy efficiency \\
\hline AFTI & $\begin{array}{l}\text { advanced fighter technology } \\
\text { integration }\end{array}$ \\
\hline
\end{tabular}

\footnotetext{
Copyright (C) 1995 by the American Institute of Aeronautics and Astronautics, Inc. No copyright is asserted in the United States under Title 17, U.S. Code. The U.S. Government has a royalty-free license to exercise all rights under the copyright claimed herein for Governmental purposes. All other rights are reserved by the copyright owner.
}

*Aerospace Engineer, AlAA, Member
\end{abstract}

\begin{tabular}{|c|c|}
\hline$A_{x p}$ & $\begin{array}{l}\text { acceleration along the flightpath, } g \\
\text { (positive forward) }\end{array}$ \\
\hline$A_{z f}$ & $\begin{array}{l}\text { acceleration normal to the flightpath, } \\
g \text { (positive up) }\end{array}$ \\
\hline$C_{L}$ & coefficient of lift \\
\hline$C_{D}$ & coefficient of drag \\
\hline$C_{L_{@ \min } C_{D}}$ & $C_{L}$ at minimum $C_{D}$ \\
\hline$C_{D_{M}}$ & $\begin{array}{l}\text { coefficient of drag caused by Mach } \\
\text { number }\end{array}$ \\
\hline$C_{D_{0}}$ & minimum drag coefficient \\
\hline c.g. & center of gravity \\
\hline DFRC & $\begin{array}{l}\text { NASA Dryden Flight Research } \\
\text { Center, Edwards, California }\end{array}$ \\
\hline EPR & engine pressure ratio \\
\hline FMS & flight management system \\
\hline GPS & Global Positioning System \\
\hline$g$ & acceleration caused by gravity \\
\hline$h$ & altitude, $\mathrm{ft}$ \\
\hline INS & inertial navigation system \\
\hline$K_{1}, K_{2}$ & drag equation coefficients \\
\hline$L / D$ & lift-to-drag ratio \\
\hline$M$ & Mach number \\
\hline MAW & mission adaptive wing \\
\hline PSC & performance-seeking control \\
\hline$q$ & dynamic pressure, $\mathrm{lb} / \mathrm{ft}^{2}$ \\
\hline
\end{tabular}

$A_{x}$

$A_{z}$

C

$C_{D}$ $c_{L}$

$C$ 


\begin{tabular}{|c|c|}
\hline$S$ & aircraft reference area, $\mathrm{ft}^{2}$ \\
\hline$T$ & net aircraft thrust, lb \\
\hline $\mathrm{TE}$ & trailing edge \\
\hline$W$ & aircraft gross weight, lb \\
\hline$\alpha$ & angle of attack, rad or deg \\
\hline$\Delta$ & change \\
\hline$\delta_{a}$ & $\begin{array}{l}\text { aileron position (symmetric }+\mathrm{TE} \\
\text { down), deg }\end{array}$ \\
\hline$\delta_{a_{o p t}}$ & $\begin{array}{l}\text { optimal (minimum drag) aileron } \\
\text { position, deg }\end{array}$ \\
\hline$\eta$ & $\begin{array}{l}\text { inclination of engine thrust relative to } \\
\text { the fuselage, rad or deg }\end{array}$ \\
\hline$\omega$ & angular frequency, $\mathrm{rad} / \mathrm{sec}$ \\
\hline
\end{tabular}

Aircraft efficiency is a critical factor for airline profitability. A 1-percent performance improvement (1-percent fuel use reduction) for the United States fleet of wide-body transports can result in savings of approximately $\$ 100$ million/yr (at current fuel costs) and an additional $\$ 20$ million/yr for each $\$ 0.10 /$ gal increase in fuel price. ${ }^{1,2,3}$

A significant amount of transport efficiency technology was developed in the 1970's and 1980's and has continued into the 1990's. The aircraft energy efficiency (ACEE) program explored maneuver load control, elastic mode suppression, gust load alleviation, ${ }^{4}$ relaxed static stability, ${ }^{5}$ and reduced-area horizontal tail design. ${ }^{6}$ The advanced fighter technology integration (AFTI)/F-111 Mission Adaptive Wing (MAW) program developed and demonstrated variable-camber control for optimization of cruise and maneuver fight conditions. ${ }^{7-9}$ The F-111 aircraft was manufactured by General Dynamics, Fort Worth, Texas, and the MAW was manufactured by The Boeing Company, Seattle, Washington.

Airbus Industrie, Blognac, Cedex, France, (a consortium of European companies) has implemented a load alleviation system on the A320 aircraft at the design stage, ${ }^{10}$ implemented an active center-of-gravity (c.g.) control system, ${ }^{11,12}$ explored improved accuracy sideslip control for drag reduction, ${ }^{13}$ and performed preliminary design work for implementation of variable camber into the A330/A340 aircraft. ${ }^{14,15}$ Extensive wind-tunnel testing of a variable-camber configuration was conducted along with some flight experiments. Benefits of variable camber include the following: ${ }^{16}$

- Improved aerodynamic efficiency (improved lift-todrag ratio $(L / D))$

- Increased Mach number $(M)$ capability

- Improved buffet boundary

- Increased operational flexibility

- Reduced structural weight

- Reduced fuel burn

- Increased aircraft development potential

Even at the design point of a state-of-the-art conventional wing, the variable-camber feature provides higher $L / D$ (fig. 1). Variable camber produced $L / D$ increases of between 3 and 9 percent and a buffet boundary increase of 12 percent. The proposed variablecamber design did not include development of a real-time adaptive optimization methodology. Spillman provided an excellent dissertation relative to the fundamentals of variable camber as applied to transports. ${ }^{17}$ American manufacturers also are actively involved in efficiency enhancement and have explored (and implemented)

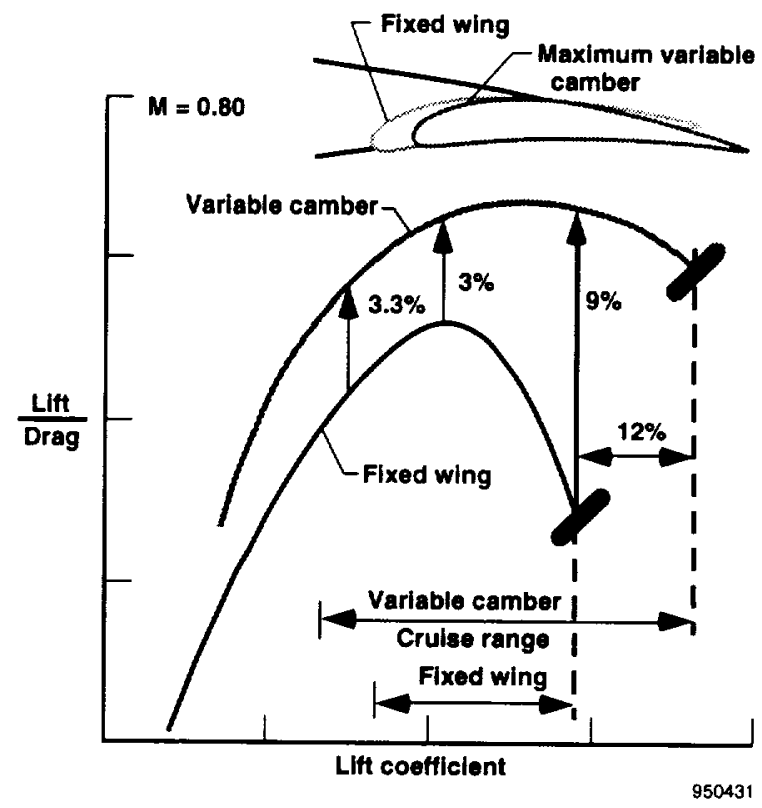

Figure 1. Wind-tunnel data illustrating benefits of a variable-camber system on a transport aircraft using a simple trailing edge flap system. ${ }^{14}$ 
fixed-point rerigging of redundant control effectors to minimize airframe drag. 1,18

The literature is replete with reports documenting trajectory optimization algorithms and their benefits relative to the economics of commercial transports. ${ }^{19-22}$ In fact, all large transports currently being produced have flight management systems (FMS) which optimize aircraft trajectory to minimize cost as a function of flight time and fuel price. However, the common theme or basis of these algorithms is that models of performance-related aspects of the aircraft are required. As a result, the optimal trajectory is only as good as the onboard FMS models. In addition to the baseline onboard model having less than perfect accuracy, airframe and propulsion system degradation are factors which affect model accuracy.

NASA Dryden Flight Research Center (DFRC), Edwards, California, is active in transitioning performance improvement technology to transport aircraft. ${ }^{23}$ The realizable performance benefits are smaller for transport aircraft than for fighter aircraft. The design of most transports has already been highly refined for good performance about the cruise flight condition. The multimission requirements for fighter aircraft result in less optimization at any given flight condition. The algorithm demonstrated on the Performance-Seeking Control (PSC) program was suitable as an early demonstration on an aircraft with large benefits to be accrued and with detailed models available.

On the other hand, the algorithm is not suitable for implementing performance optimization on transports primarily because of the much smaller benefits accruable and the fact that the algorithm was heavily based on $a$ priori model data and absolute measurement accuracy. As a result, DFRC is exploring the application of measurement-based adaptive optimal control for performance improvement using redundant control effectors. As the terminology implies, adaptive optimization compensates for all unique characteristics of the system being optimized by continuously feeding back measurements of parameters that reflect the optimization objective, such as fuel flow (minimize) or velocity (maximize). For example, symmetric aileron deflection can be applied to optimally recamber the wing for all aircraft configurations and flight conditions.

Pioneering work in the field of optimizing controls was conducted by Draper and $\mathrm{Li}$ more than $40 \mathrm{yr}$ ago to maximize an internal combustion engine as a function of ignition timing and fuel-air ratio for constant engine speed and fuel flow. ${ }^{24} \mathrm{~A}$ similar approach was applied by Vasu to maximize the pressure ratio of a jet engine. ${ }^{25}$

A feasibility study explored a prototype adaptive control law on a high-fidelity, nonlinear simulation of a firstgeneration (narrow-body) jet aircraft which optimized wing-aileron camber for minimum aircraft drag at a given fight condition. ${ }^{26}$ This technology applies to selected current generation aircraft and to the entire next generation of fly-by-wire aircraft and could be a requirement for future designs, such as the proposed New Large Aircraft. ${ }^{27}$ Adaptive performance optimization could play an important role in improving economic factors by maximizing aircraft performance; early research is required for timely technology transition.

The key technological challenge to in-flight performance optimization for transport aircraft is identification of very low levels of incremental drag. To provide an effective optimization algorithm, identification of incremental drag levels of 1 percent or less will be required.

This paper addresses (using a wide-body transport simulation) the practical application of real-time performance optimization and concentrates on onboard measurement and calculation of incremental drag from forced response maneuvers. The approach is based on using an inertial navigation system (INS) with blended Global Positioning System (GPS) information which can produce very accurate linear and angular displacement, velocity, and acceleration measurements. Along with other more conventional measurements, this information is used to calculate winds and angle of attack, $\alpha{ }^{28}$ Thrust is estimated from a representative engine model as a function of measured variables. The lift and drag equations are then used to calculate lift and drag coefficients, $C_{L}$ and $C_{D}$. An expression for $C_{D}$, a function of parasite drag, induced drag, and aileron drag, is solved recursively from forced response maneuvers. Estimates of the parasite drag, curvature of the aileron drag variation, and optimal aileron position for minimum drag are produced. Results of instrumentation sensitivity studies are also presented.

\section{Adaptive Control Background}

Application of adaptive control to aircraft has been ongoing for more than $30 \mathrm{yr}$ with varying degrees of success. These applications have often centered on handling quality-related control system improvements, 
which often involve optimizing a very subjective, often illdefined criteria typically involving handling qualities, for example, pilot ratings. Because of the subjective nature of handling qualities, adaptive control techniques are not necessarily well-suited approaches to the problem. Also note that in many flight control applications, use of adaptive techniques has led to safety concerns about gain and phase margin reductions. Such reductions have contributed to stability and control problems.

As such, adaptive control, as applied to flight control, has not found wide acceptance within the aerospace community. Lack of interest in adaptive control is partially caused by the satisfactory results that have been obtained using conventional design techniques and by lack of an overriding reason to obtain similar results by using more complex techniques.

Application of adaptive control is particularly advantageous when the optimization objective is well defined and there are significant unknowns about the aircraft and its operation. Application of adaptive optimal control to quasi-steady performance optimization has clear benefits that are not achievable in control design processes that are tailored to handling qualities issues. Quasi-steady performance optimization has well-defined objectives (i.e., minimize drag). For this reason, adaptive optimal control is well-suited to performance optimization. In addition, application of adaptive optimal control, using a measured performance metric, is insensitive to modeling inaccuracies and measurement biases. Because low frequency constrained maneuvers are proposed, stability- and control-related safety issues and affects on ride qualities are greatly minimized.

For the Airbus Industrie and U.S. cases in which variable-camber performance optimization have been explored, neither devoted serious attention to a real-time performance optimization algorithm. The AFTI/F-111 MAW system used either predetermined deflection schedules or a real-time, trial-and-error approach for camber control. ${ }^{7,8}$ In the Airbus Industrie case, only model-based or experimentally determined scheduling was briefly mentioned as a means of camber control. ${ }^{14}$

\section{Performance-Seeking Control}

The F-15 PSC program ${ }^{29}$ developed a technical approach and methodology that can be used to enhance the performance of fighter and transport (subsonic and supersonic) aircraft. Figure 2 shows the PSC algorithm. It comprises three main modules: identification, modeling, and optimization. However as currently implemented, the F-15 PSC algorithm requires models that accurately predict flight hardware performance variations. In addition, the identification process depends on accurate absolute measurements of the inputs and outputs of the system being optimized. The F-15 aircraft was

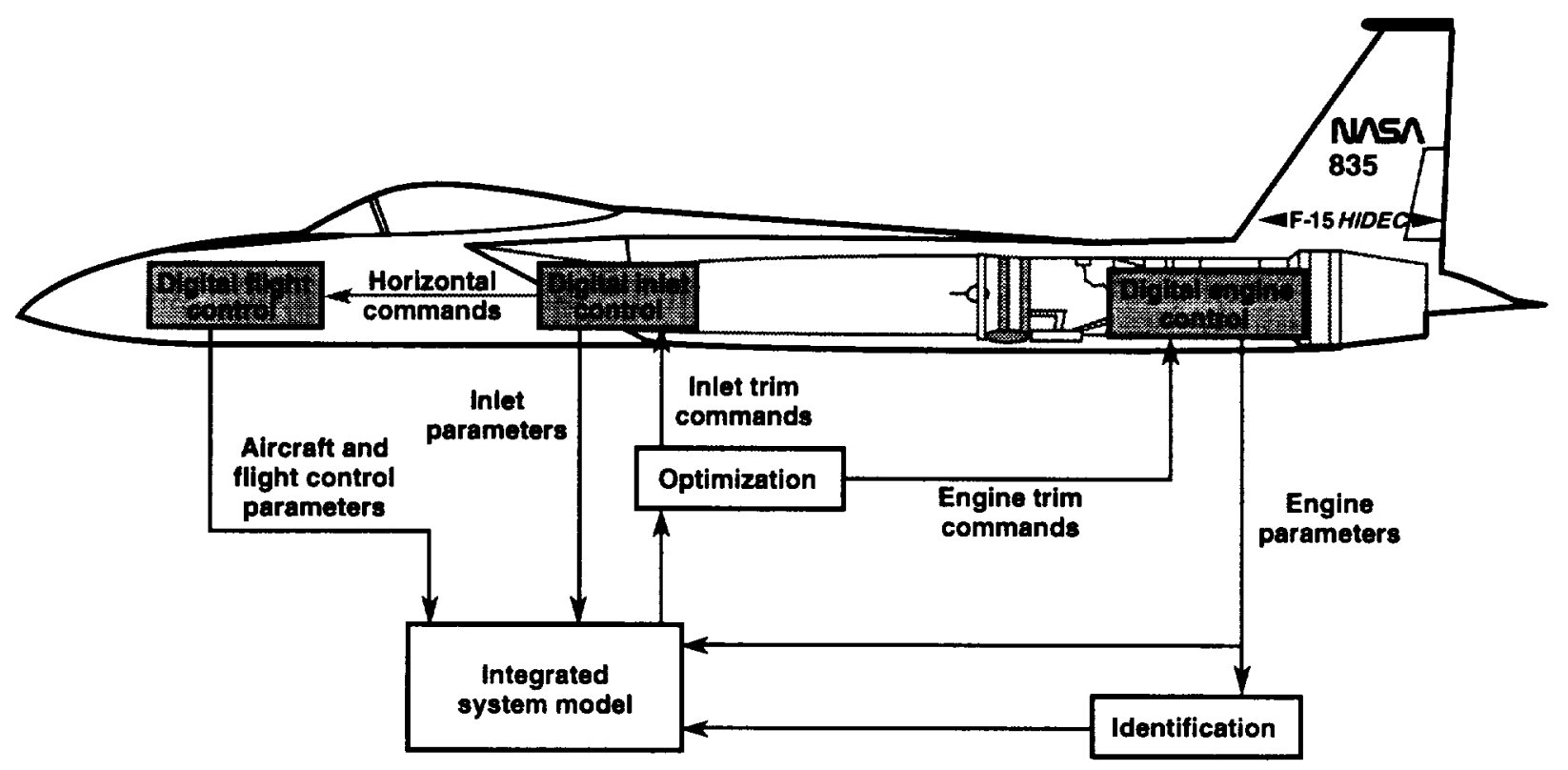

Figure 2. Performance-seeking control. ${ }^{29}$ 
manufactured by McDonnell Douglas Corporation, St. Louis, Missouri.

Frequently in control problems, perturbation feedback control techniques are used. In these cases, biases on measurements do not affect results; however, the F-15 PSC approach is neither perturbation based nor closedloop but rather relies on absolutes and open-loop commands. Several means were explored within the context of the F-15 PSC algorithm, directed at addressing the bias problem, but to no avail. The real-time identification of the biases would be ideal but was not possible because of the limited sensor set available on the F-15 aircraft. ${ }^{30}$ The solution used for flight test was $a$ priori identification of key biases from ground-based tests and their inclusion in the flight algorithm. In an operational environment, a priori identification of biases is unacceptable.

Application of adaptive optimal techniques to performance optimization does not require accurate models or absolute measurements. The adaptive optimal approach is based on real-time estimation of gradients of performance measures to control variables. These gradients are based on flight measurements and not based on predictions. In addition, because gradients are used, the approach is insensitive to measurement biases.

An adaptive optimal approach is ideally suited for use on operational "fleet" aircraft where there is uncertainty in the aircraft model and absolute measurement accuracy. Likewise, adaptive performance techniques have a valuable role for commercial aircraft where small benefits over a 20-30 yr service life can produce significant cost savings.

\section{Transport Performance Optimization Issues}

Many issues enter into the performance optimization problem for subsonic transport aircraft. Foremost, there must be the potential for optimization, which implies redundant control effector capability (i.e., more than one means of trimming out the forces and moments to maintain a steady-state flight condition). Most aircraft have significant capability in this area although taking advantage of this capability is a different issue. Performing optimization from a condition that is already fine-tuned (based on wind tunnel and flight testing) places increased demands on high-quality instrumentation to sense small differences in an unsteady environment.

\section{Control Effectors}

A wide range of controls or variables can potentially play a role in performance optimization for current and future generation aircraft. These controls and variables include elevator, horizontal stabilizer, outboard aileron, inboard aileron, flaps, slats, rudder, c.g., thrust modulation, thrust vectoring, and differential thrust (fig. 3). In addition, the potential for flightpath control using only differential thrust has been demonstrated. ${ }^{31}$ Spoilers are probably not an option for performance optimization because they only increase drag. Although if

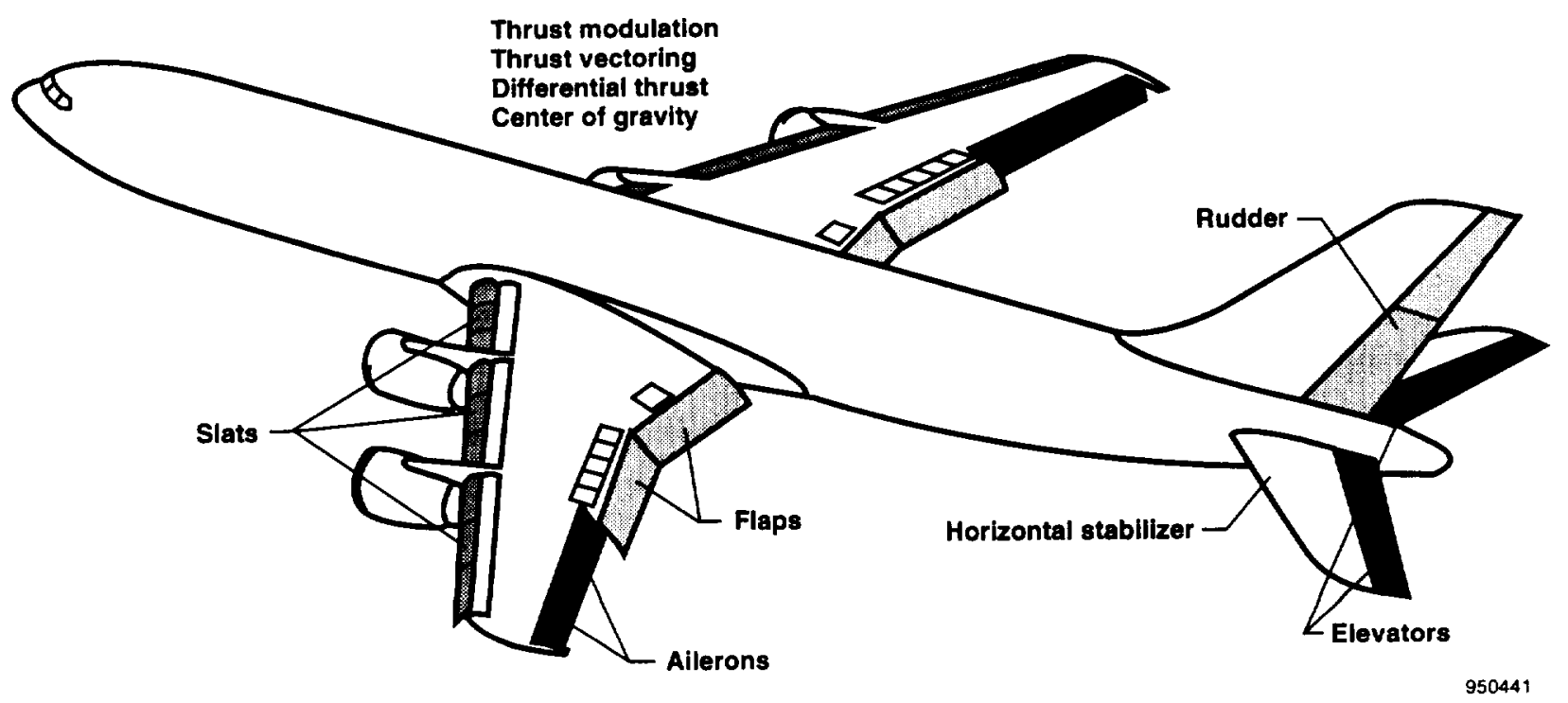

Figure 3. Aircraft performance optimization potential. 
a case exists which requires drag modulation, spoilers are a viable controller.

Note that delta-wing aircraft configurations generally have less optimization potential than tail-configured aircraft because delta wings have fewer independent control effectors. Fewer effectors reduce the potential for optimization. The main difference is that there is no independent horizontal stabilizer-elevator for delta-wing configurations, thus removing a major potential for wing optimization. These differences do not imply that more sophisticated wing leading- and trailing-edge (TE) devices, which would permit some degree of camber optimization, could not be implemented. A canard can significantly increase the optimization potential for conventional and delta-wing configurations.

\section{Instrumentation}

Successfully implementing a performance optimization algorithm requires high-quality, sensitive instrumentation. Fortunately, the instrumentation being implemented in today's most advanced transports for FMS operation (trajectory and navigation control) is very good. Although a large number of cost functions or variables exists that could conceivably be used for optimization, only a few basic aircraft measurements are required for cruise drag minimization. To minimize fuel flow at constant Mach number and altitude conditions requires accurate fuel-flow indications, such as either fuel flow, fuel valve position, throttle position, or thrust.

In-lieu of direct fuel-flow measurements, engine pressure ratio (EPR) measurements combined with a representative engine model, which is a function of flight condition, will provide accurate incremental fuel-flow or thrust results. Although in absolute terms the accuracy required would be demanding, the optimization problem only places demands on perturbation accuracy, which is not affected by biases. Maximizing velocity for constant altitude and fuel flow requires accurate perturbation measurements of velocity, flightpath acceleration, or both. Effects of measurement bias and resolution are evaluated and discussed in this paper.

\section{$\underline{\text { Real-Time Drag Minimization }}$}

Preferably, performance optimization could be accomplished using responses to pilot or autopilot and FMS commands. However, with tight pitch-rate, pitchattitude, and altitude and velocity hold control laws, external environment-based disturbances and associated responses would, generally, be small. As a result, forced excitation is required to ensure identifiability. The requirement for forced excitation must be tempered by the additional requirement that neither handling nor ride qualities are noticeably impacted. In turn, this requirement dictates the range of excitation frequencies and amplitudes. Parameter identification of the performancecontrol sensitivity could be done using any of a number of techniques covering a broad range of sophistication. (Iliff demonstrated a maximum likelihood lift and drag estimation and analysis technique for fighter aircraft using dynamic maneuvers.) ${ }^{32}$ System optimization is essentially a direct fallout of the parameter identification methodology selected.

\section{Adaptive Performance Optimization Algorithm}

From a real-time implementation perspective, the key technological challenge is identification of low levels of incremental drag. To provide an effective optimization algorithm, estimation of incremental drag levels of 1 percent or less will be required. Obtaining absolute drag measurements of this accuracy requires detailed analysis and precise engine modeling. Incremental drag values in this range are more readily achievable. Incremental drag assessment in the 1-drag count range (approximately $1 / 3$ percent) has been determined from flight as part of a drag reduction program for the MD-11 aircraft (McDonnell Douglas, Long Beach, California). ${ }^{33}$ Data defining the flight-determined drag polar for the C-17 aircraft (McDonnell Douglas, Long Beach, California) has been reported in reference 34 . Other wide-body flight data indicates incremental drag accuracy in the 1-drag count range for a recambering experiment.

Adaptive performance optimization (APO) feasibility studies $^{23,26}$ (using a first-generation narrow-body jet transport simulation) have practical difficulties in an operational flight scenario because of measurement bias and resolution characteristics. The optimization approach presented in this paper is directed at identifying unknown drag equation characteristics (including the minimum drag aileron position) from a forced response, smooth, low frequency maneuver then setting the aileron to the estimated minimum drag position. The analysis procedure follows the general methodology used for postflight performance analysis with simplifications suited to the determination of incremental drag.

The process is based on using an INS with blended GPS information which can produce accurate linear and angular 
displacement, velocity, and acceleration measurements. Along with true airspeed, this information is used to calculate winds and angle of attack. ${ }^{28}$ The required transformations can then be performed to produce flightpath axes accelerations. Thrust is estimated from a representative steady-state engine model as a function of measured variables. The lift and drag equations are then used to calculate $C_{L}$ and $C_{D}$.

$$
\text { Lift }=q S C_{L}=W A_{z_{f p}}-T \sin (\alpha-\eta)
$$

where

$$
\begin{aligned}
& q=\text { dynamic pressure } \\
& S=\text { aircraft reference area } \\
& C_{L}=\text { coefficient of lift } \\
& W=\text { aircraft gross weight } \\
& A_{z}=\text { acceleration normal to the flightpath } \\
& T=\text { net aircraft thrust } \\
& \alpha=\text { angle of attack } \\
& \eta=\text { inclination of the engine thrust relative }
\end{aligned}
$$

Aircraft weight and center of gravity are calculated based on takeoff weight and fuel flow and then smoothed.

$$
\operatorname{Drag}=q S C_{D}=T \cos (\alpha-\eta)-W A_{x_{f p}}
$$

where $A_{x_{f p}}$ is acceleration along the flightpath. Thrustrelated ram effects are assumed aligned with the gross thrust axis and are included in the other terms. Equation 3 is an expression for $C_{D}$ which is a function of parasite drag, induced drag, and aileron drag.

$$
\begin{aligned}
C_{D}= & C_{D_{0}}+K_{1}\left[C_{L}-C_{L_{@ \min } C_{D}}\right]^{2} \\
& +K_{2}\left(\delta_{a}-\delta_{a_{o p t}}\right)^{2}
\end{aligned}
$$

The drag equation coefficient $\left(K_{1}\right)$ and lift coefficient at minimum drag coefficient $\left(C_{L @ \min } C_{D}\right)$ are selected from previous baseline aircraft flight data; $\delta_{a}$ is the aileron position. Equation 3 is then solved from forced response excitation data. Algorithm solutions can range from continuous to batch operation. These results use a batch approach. Estimates of the parasite drag or minimum drag coefficient, $C_{D_{0}}$, curvature of the aileron drag variation, $K_{2}$, and optimal aileron position, $\delta_{a_{o p t}}$, are produced.

In this study, values of $K_{1}$ and $C_{L_{@ \min } C_{D}}$ are assumed to be independent of the symmetric aileron position for small deflections. In actuality, symmetric aileron deflection would result in a small change to spanwise lift distribution and, in turn, to induced drag characteristics of the wing. This effect would cause a small variation in the value of $K_{1}$ as a function of symmetric aileron position. Sensitivity of the APO algorithm to this effect should be addressed in future studies.

The formulation of equation 3 is not unique; the important element being that the first-order effects of aileron-induced drag be represented in the $C_{D}$ equation in a plausible manner. Care should be taken not to over parameterize the problem; independence of the various estimates must be maintained to provide meaningful results. 'The actual drag reduction is

$$
\Delta \operatorname{Drag}=q S K_{2}\left(\Delta \delta_{a}\right)^{2}
$$

Other performance related calculations, such as specific fuel consumption and range, can be calculated postflight.

\section{Aircraft Simulation Model}

The APO algorithm was evaluated using a simulation of a first-generation wide-body transport. The simulation is high fidelity and covers the full aircraft envelope. The primary control system has simple rate feedback, while the altitude- and velocity-hold autopilot modes were designed with feedback to the stabilator and throttle, respectively. The aileron drag characteristics were modified (based on unpublished simulation and flight data of similar configurations) to provide a quadratic drag variation with symmetric aileron displacement. All the simulation runs were initiated at Mach 0.83, at an altitude of $37,000 \mathrm{ft}$, and at a weight of $408,000 \mathrm{lb}$. Fuel burn was simulated as a function of thrust. Low-order thrust versus throttle-lever dynamics are in the simulation. Light turbulence was used for all runs to provide a realistic signal-to-noise ratio. 
Figure 4 shows the variation of thrust required for trimmed steady-state flight as a function of symmetric aileron displacement. The minimum drag reduction of $364 \mathrm{lb}$ (1.5 percent) occurs at approximately $4.5^{\circ}$ symmetric aileron deflection.

\section{$\underline{\text { Results and Discussion }}$}

Figure 5 presents the forced excitation response, with altitude- and velocity-hold modes on, to a raised cosine $(1.0-\cos (\omega t))$ symmetric aileron command with a $300-\mathrm{sec}$ duration. (The $\omega$ is the angular frequency.) The simulated responses used in the analysis are flightpath axes accelerations, angle of attack, thrust, weight, and symmetric aileron deflection. For this analysis, it was assumed that the angle of attack is calculated from INS velocities and true airspeed. In addition, the flightpath accelerations are calculated from body-axes accelerations rotated through angle of attack, and thrust is obtained as a function of EPR and flight condition. The variation of $C_{D}$ with $\delta_{a}$ does not present a clear picture of the minimum drag point (fig. 6).

Figure 7 presents $\Delta C_{D}=C_{D}-K_{1}\left[C_{L}-C_{L_{@ \min } C_{D}}\right]^{2}$ with $\delta_{a}$. Correcting for the $C_{L}$ variations produces a much clearer picture of the drag minimization process. The quadratic variation of $\Delta C_{D}$ is clear, but there still is a significant difference between increasing and decreasing $\delta_{a}$ commands. (Note that the $C_{D}$ and $\Delta C_{D}$ incremental scales are the same for figures 6-9 for ease of comparison.)

A close look at the time histories reveals that Mach number variations exist which could, in turn, contribute a change in drag as a function of Mach number via a $C_{D_{M}}$ effect. To improve the accuracy of the analysis, a linear $C_{D_{M}} \Delta M$ term was added to equation 3 with $C_{D_{M}}$ added to the list of variables to be estimated. Figure 8 presents the $\Delta C_{D}$ variation (including the Mach number effect correction) with $\delta_{a}$ and the quadratic variation is now well-defined and agrees with the minimum drag point of figure 4.

\section{Sensitivity to Baseline Data}

The good results presented in figure 8 may not be all that surprising in view of the fact that the simulation output variables are perfect with, at most, some white noise effects manifested from the turbulence. Assurance of analysis insensitivity to all known effects must be verified.

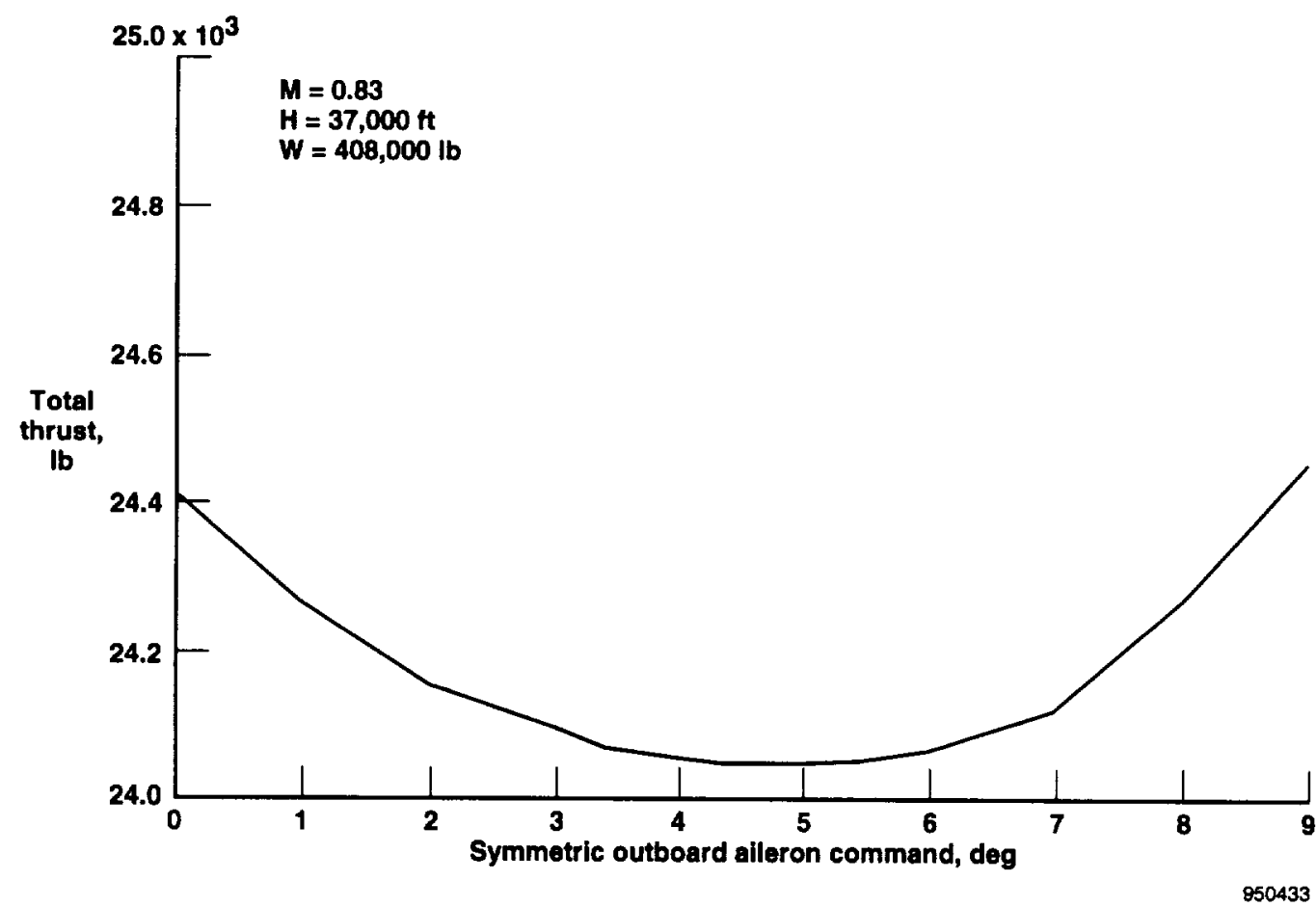

Figure 4. Variation of trimmed thrust required as a function of symmetric outboard aileron. 

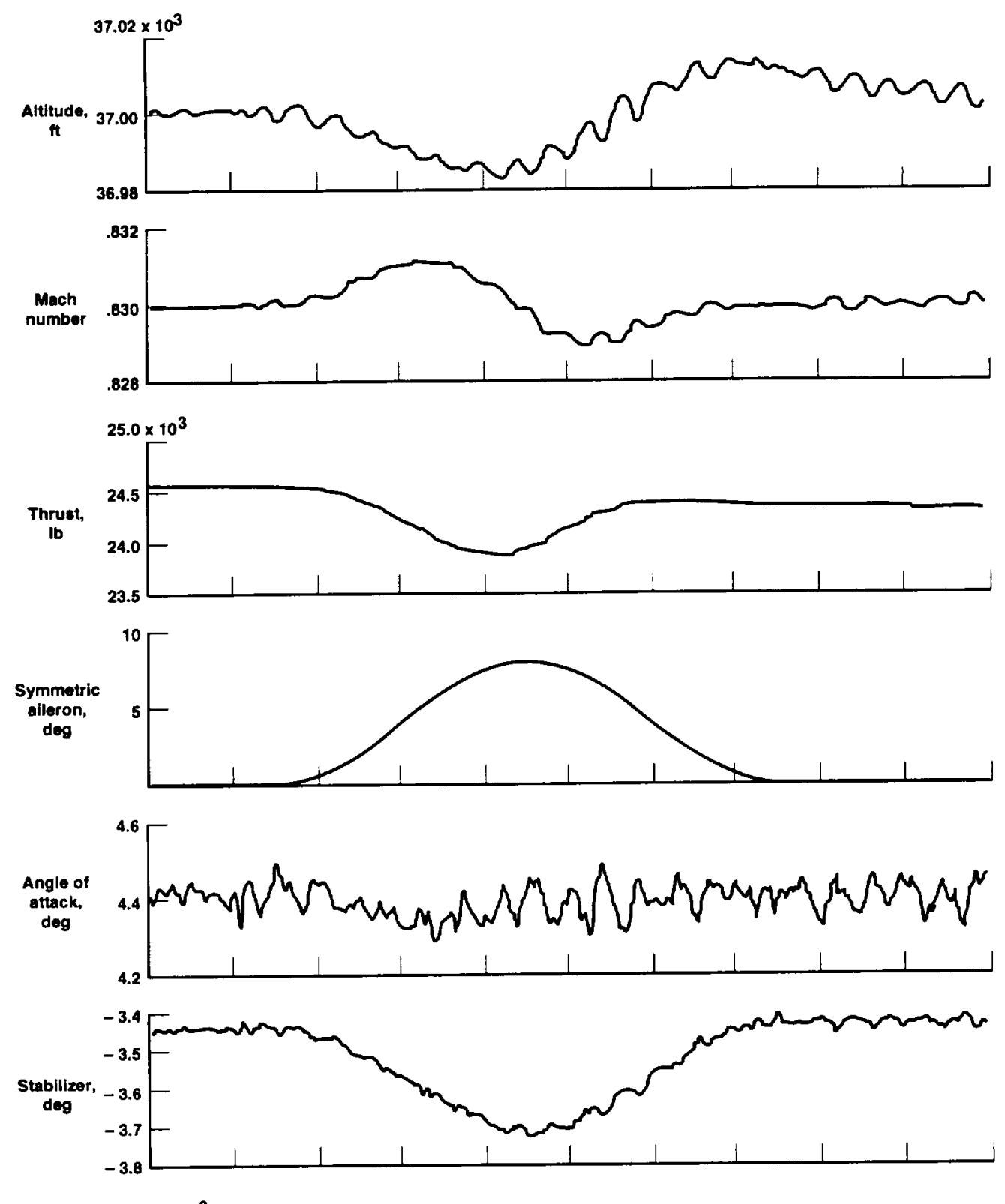

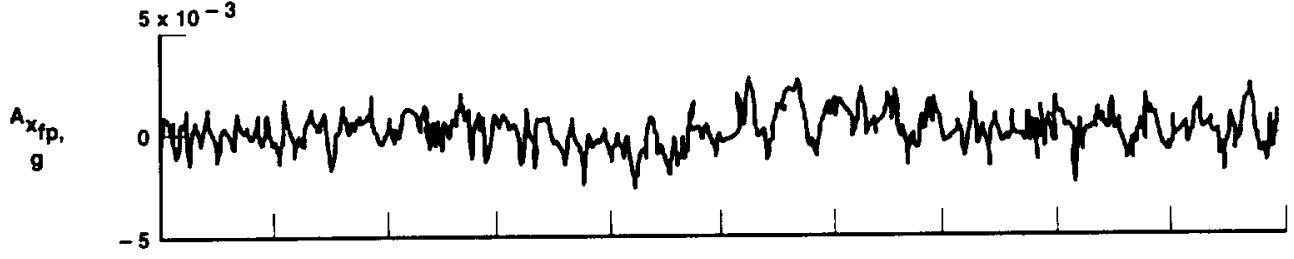

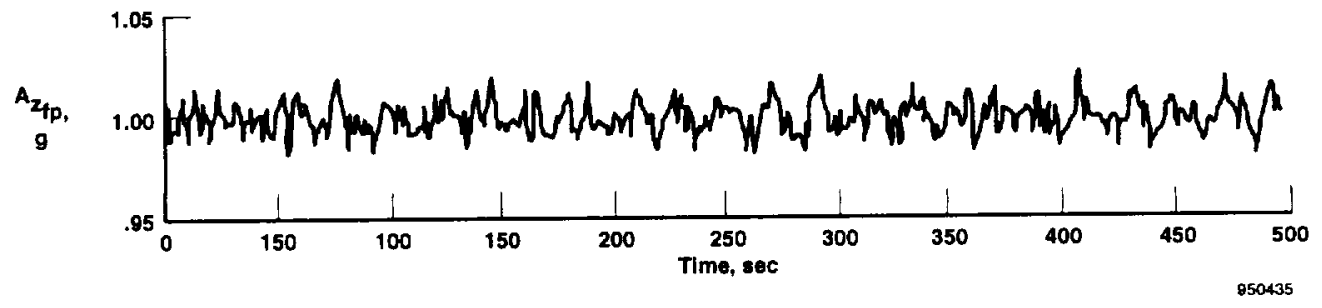

Figure 5. Time history of drag minimization maneuver. 


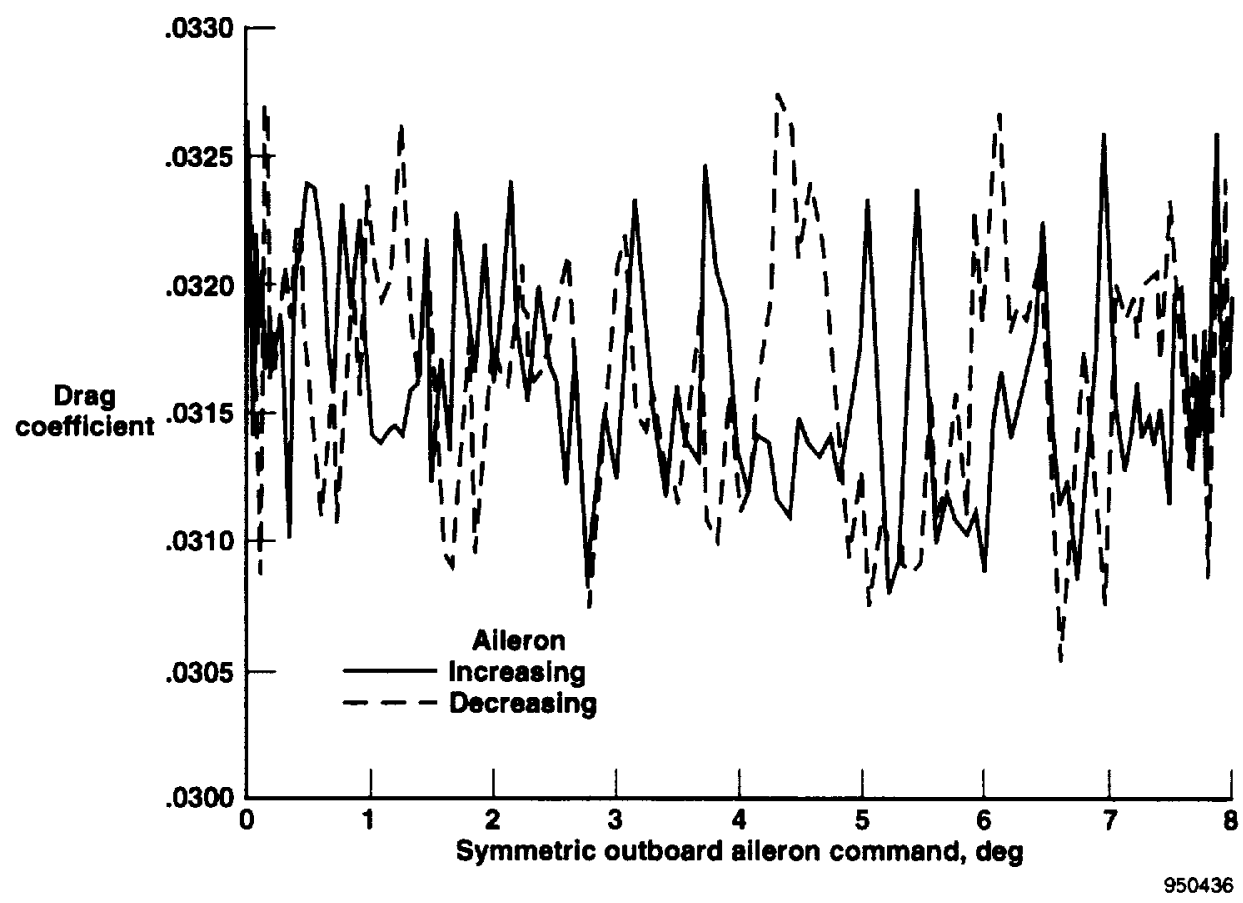

Figure 6. Variation of calculated drag coefficient as a function of symmetric outboard aileron.

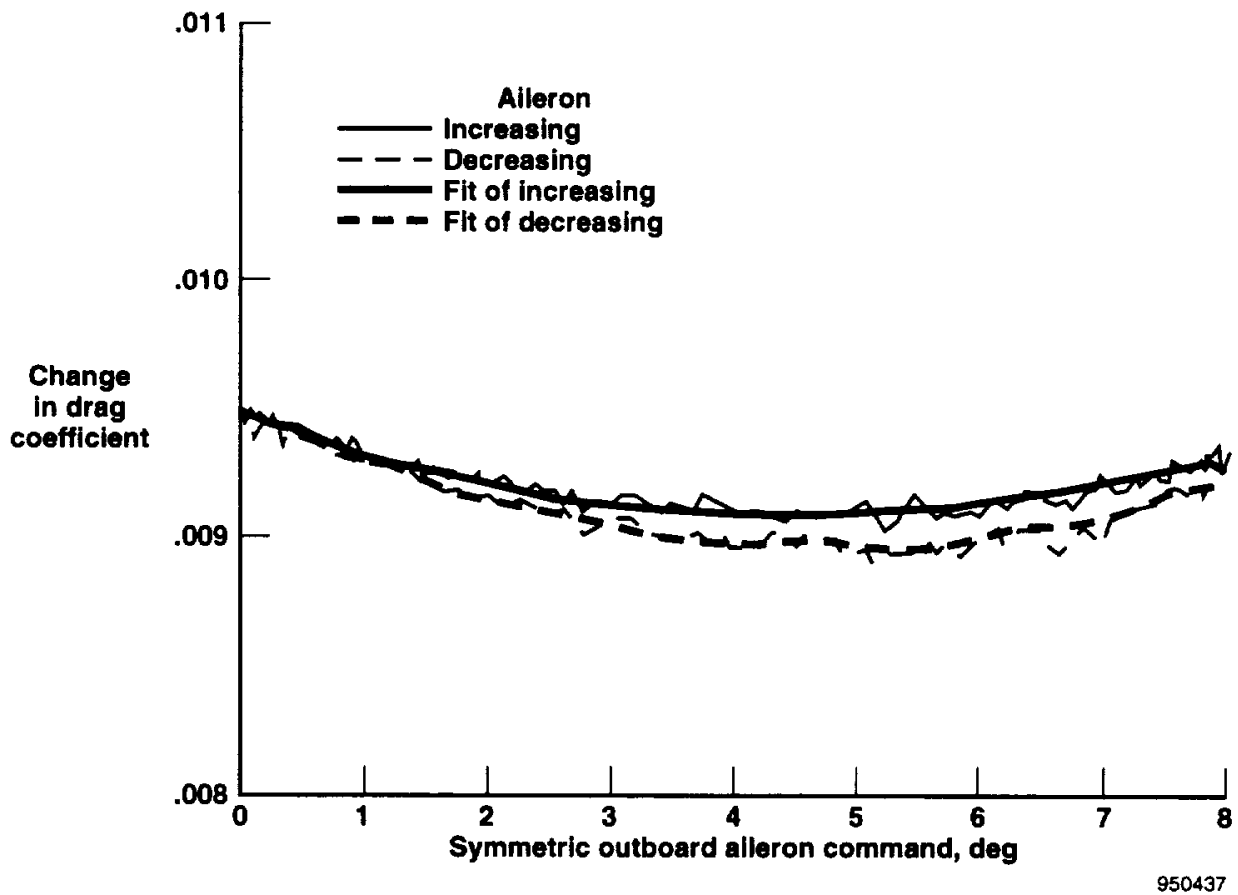

Figure 7. Change in drag coefficient as a function of symmetric outboard aileron. 


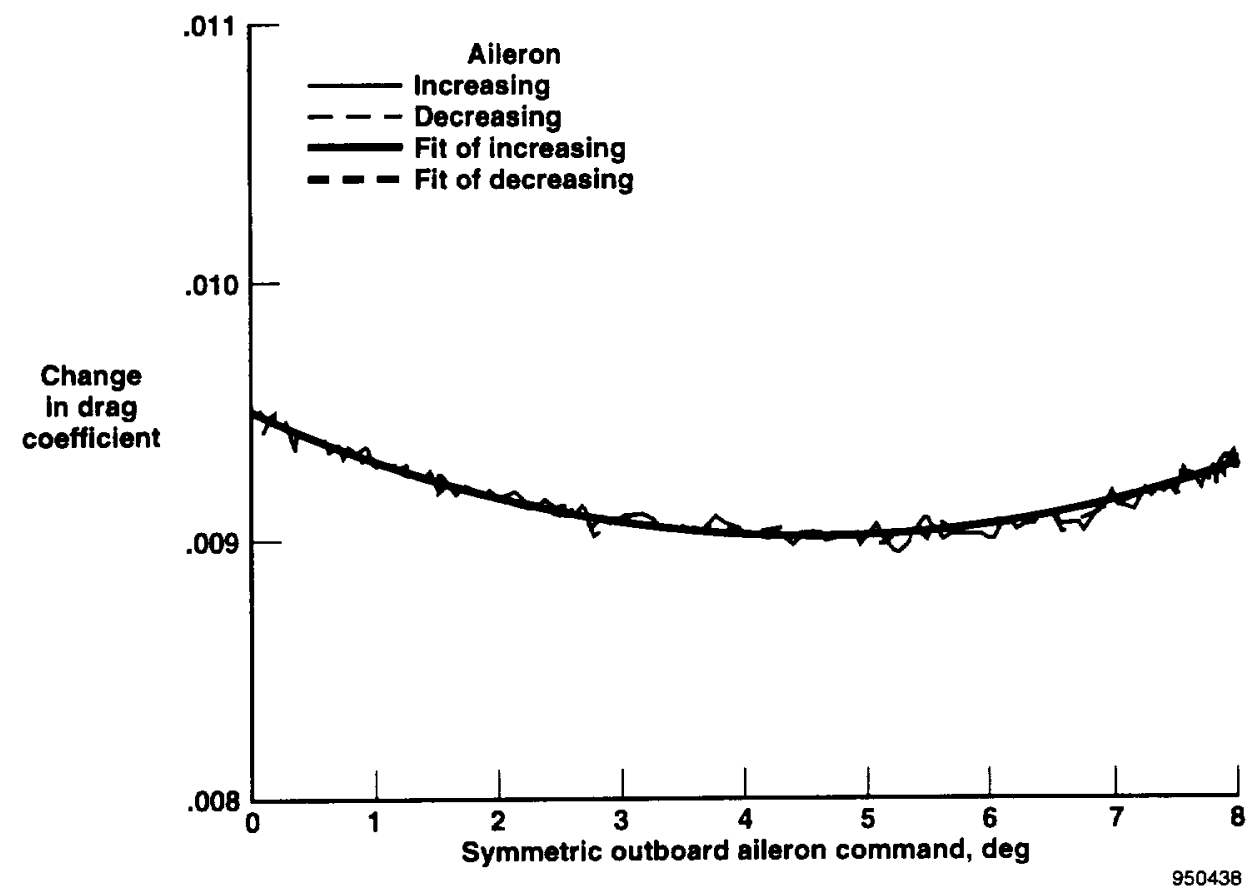

Figure 8. Change in drag coefficient (corrected for Mach number) as a function of symmetric outboard aileron.

To minimize the variation or inaccuracy of the estimates, or both, a priori values of $K_{1}$ and $C_{L_{@ \min } C_{D}}$ are used. These parameters characterize the quadratic nature of the $C_{L} / C_{D}$ variation. Separate parametric variations of these a priori parameters of \pm 25 percent and \pm 50 percent on $K_{1}$ and $C_{L_{@ \min } C_{D}}$ respectively were performed. These variations produced less than $0.1^{\circ}$ variation on the optimal symmetric aileron value $\left(4.5^{\circ}\right)$. As a result, the optimal solution appears insensitive to these a priori parameters.

\section{Measurement Bias Effects}

For absolute performance analysis, measurement bias is a limiting factor on analysis accuracy. However, the formulation of this APO analysis algorithm is designed to be insensitive to measurement bias. The following biases (applied one at a time) produced less than $0.1^{\circ}$ variation on the optimal symmetric aileron value:

\begin{tabular}{ll}
\hline \multicolumn{1}{c}{ Parameter } & \multicolumn{1}{c}{ Bias } \\
Angle of attack & $0.5^{\circ}$ \\
Acceleration along the flightpath & $0.02 \mathrm{~g}$ \\
Acceleration normal to the flightpath & $0.02 \mathrm{~g}$ \\
Net aircraft thrust & $1500 \mathrm{lb}$ \\
Aircraft gross weight & $10,000 \mathrm{lb}$ \\
\hline
\end{tabular}

A bias on the symmetric aileron measurement produces an equivalent change on the optimal solution, but in true terms, the solution is unaffected. Bias insensitivity is significant relative to the analysis because measurement biases are common. Note also that these findings apply in spite of the fact that the equations are nonlinear.

\section{$\underline{\text { Resolution Effects }}$}

Operating near or at the resolution limits of instrumentation is potentially a serious problem, and the analysis procedure must be insensitive to these quantization effects. Formulation of this APO analysis algorithm is not overly sensitive to resolution resulting, in part, from the regression technique employed. The results of figure 8 are repeated in figure 9 but with the following resolution set:

\begin{tabular}{ll}
\hline \multicolumn{1}{c}{ Parameter } & Resolution \\
Aileron position & $0.1^{\circ}$ \\
Angle of attack & $0.1^{\circ}$ \\
Acceleration along the flightpath & $0.002 \mathrm{~g}$ \\
Acceleration normal to the flightpath & $0.002 \mathrm{~g}$ \\
Net aircraft thrust & $150 \mathrm{lb}$ \\
Mach number & 0.001 \\
\hline
\end{tabular}




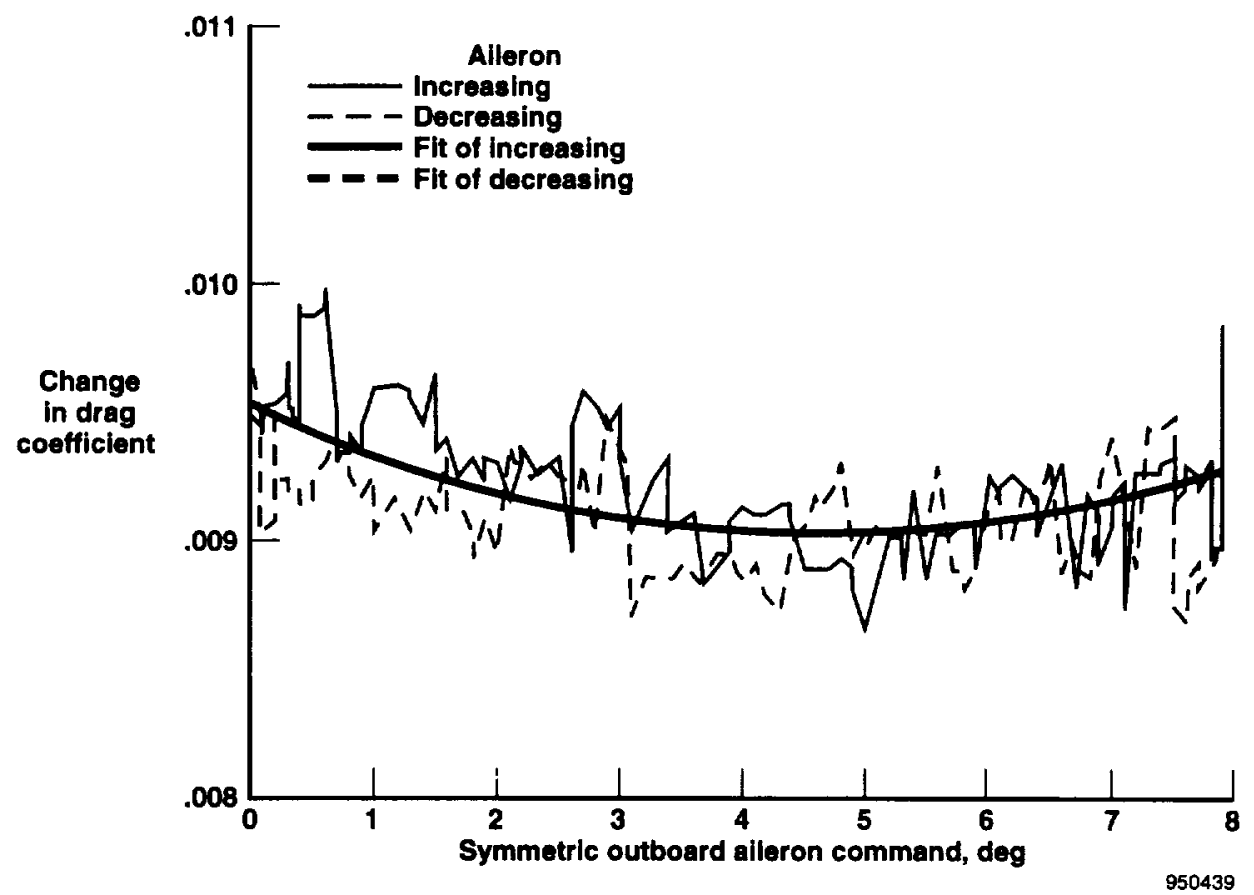

Figure 9. Change in drag coefficient (corrected for Mach number) as a function of symmetric outboard aileron (with resolution).

The analysis with resolution produced less than $0.2^{\circ}$ variation from the optimal symmetric aileron value case of figure 8.

The algorithm appears to be most sensitive to thrust resolution. An increase in the thrust resolution to $300 \mathrm{lb}$ changes the optimal symmetric aileron value by $0.4^{\circ}$. In general, however, the optimal solution is relatively insensitive to these resolution effects.

\section{Thrust Accuracy}

Although thrust is not measured, it is determined based on EPR and flight condition measurements and a representative engine model. The thrust calculations will tend to be the least accurate of all inputs to the analysis process. Constant errors in the thrust level are not a problem. However, thrust is based on interpolation of steady-state thrust tables; hence, inaccuracies caused by lack of modeled engine dynamics, whether they accrue from throttle lever motion or atmospheric effects, will occur. A cursory evaluation of this effect was conducted by calculating a thrust value to be fed into the analysis as a linear variation with throttle lever. Figure 10 shows the variation of thrust with throttle lever for the data of figure 5 along with a linear fit of the data. Using this relationship in the analysis produced an error of less than $0.1^{\circ}$ in the optimal symmetric aileron solution.
Minimizing fuel flow at constant Mach number and altitude conditions requires accurate fuel-flow indications, such as fuel flow, fuel valve position, throttle position, or thrust. In-lieu of direct fuel-flow measurements, EPR measurements combined with a representative engine model, which is a function of flight condition, will provide sufficiently accurate incremental fuel-flow or thrust estimates.

A more realistic and interesting situation is the sensitivity of the solution to an error in the slope of the thrust as a function of the throttle of the linear fit (fig. 10). A bias of the linear relationship is addressed in the Measurement Bias Effects sub-section. An error in the slope (in addition to a bias error) would be representative of a miss-modeling of the engine characteristics via a table look-up process. Figure 10 also shows a linear thrustthrottle lever variation with a 10-percent increase in slope and with the constant adjusted so that the linear relationship has the correct thrust level at the trim flight condition. The constant has the same effect as a bias error and, therefore, is a reasonable assumption. The 10-percent error in slope produced a negligible (less than $0.1^{\circ}$ ) difference in the optimal aileron solution. A 20-percent error produces a $0.4^{\circ}$ difference in the optimal aileron solution. In referring back to figure 6 , even a $0.5^{\circ}$ error in 


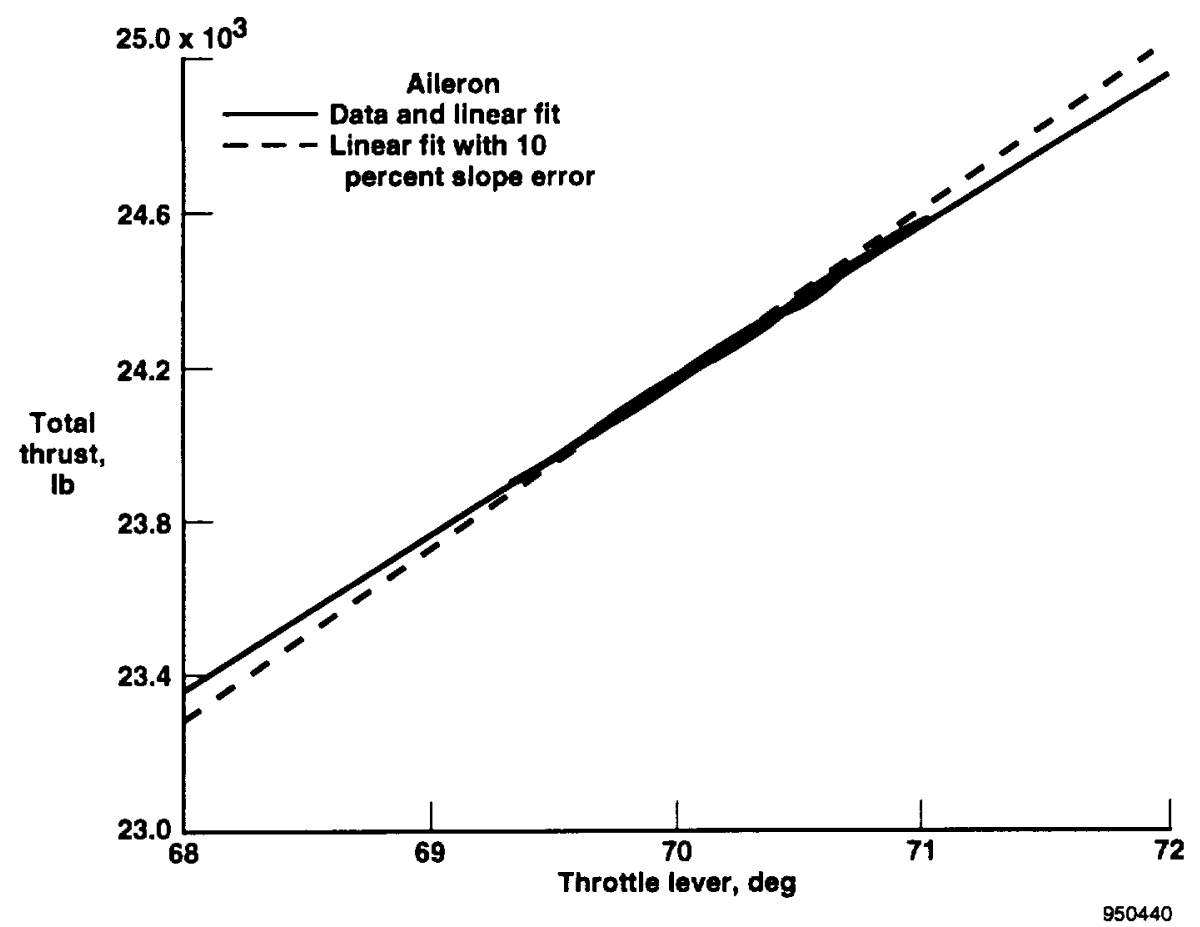

Figure 10. Variation of total thrust with throttle lever (data of figure 5).

the optimal solution is insignificant because the variation of drag with aileron is shallow.

\section{Hardware Implementation}

Selected aircraft have the hardware (symmetric aileron trim deflection capability) required to perform onboard performance optimization and, therefore, would only require a relatively simple set of optimization software. Algorithm redundancy is not required because the algorithm is a non-safety-of-flight system. This nonsafety-of-flight aspect can be assured by having APO in a discretionary mode with very limited rate and position authority. The algorithm can be a completely independent set of code and, therefore, avoid the issues of integration with the FMS. The algorithm can be thought of as a slow, limited authority trimmer.

For aircraft that do not currently have the hardware capability of moving the outboard ailerons symmetrically, a relatively simple modification consisting of adding a low frequency, limited authority, trim actuator in series with the mechanical command to the outboard aileron actuator would suffice. The slow actuator rate plus limited authority minimizes safety-related issues.

\section{Related Issues}

The forced excitation requirement of real-time adaptive optimization generally attracts concern and, therefore, some discussion is in order. For the very steady conditions of cruise flight optimization, forced excitation is the only means of performing identification and adaptive optimization. No other means of identifying the desired characteristics of the aircraft exist. The low frequency raised cosine excitation was proposed to minimize interaction with the autopilot inner-loops and to minimize the effect on ride qualities. This function results in a negligible incremental normal acceleration $(\approx 0.001 \mathrm{~g}$ ) and precludes concern for other aircraft wear and tear, such as control surfaces and engines. Although minimal interactions between the explicit excitation and the innerloop autopilot modes were observed, other aircraft, control surface combinations, or both, could produce degraded inner-loop performance. In such instances, inner-loop controller lead as a function of the explicit excitation function could be used to minimize inner-loop performance degradation. ${ }^{26.35}$

Because aircraft specific variations play a significant role in the actual amount of performance improvement accruable, using previous optimality results as initial 
conditions can speed up optimality convergence for subsequent flights.

Different flight conditions have also been evaluated, and it appears that very little, if any, algorithm tuning is required. Exploratory algorithms have also been evaluated for optimization in the climb-to-altitude flight segment. ${ }^{35}$

\section{Concluding Remarks}

This report describes a conceptual design of a real-time, adaptive-optimal performance algorithm for application to subsonic transports. Preliminary simulation results indicate the approach is very promising. The algorithm implementation is simple and appears to have robust performance characteristics.

Because the performance optimization problem is searching for small benefits, instrumentation may appear to be a critical factor. However, realistic instrumentation and measurement effects have been evaluated, demonstrating that the algorithm is insensitive to these effects.

While this study demonstrates that the algorithm looks promising, real world effects cannot be predicted or simulated accurately. A flight evaluation of the adaptive performance optimization algorithm is required to research the issues of operational use; benefits can only be determined in-flight.

\section{$\underline{\text { References }}$}

1 "Long Live the Leviathan," Flight International, Sept. 15-21, 1993, pp. 30-31.

2 "P\&W Plans PW4000 Improvement Tests," Flight International, June 30-July 6, 1993, pp. 11.

${ }^{3}$ Szodruch, J., "Viscous Drag Reduction on Transport Aircraft," AIAA 91-0685, 1991.

${ }^{4}$ Johnson, J.F., Accelerated Development and Flight Evaluation of Active Controls Concepts for Subsonic Transport Aircraft - Volume I - Load Alleviation/ Extended Span Development and Flight Tests, NASA CR-159097, 1979.

${ }^{5}$ Guinn, Wiley A., Jerry J. Rising, and Walt J. Davis, Development of an Advanced Pitch Active Control System for a Wide Body Jet Aircraft, NASA CR-172277, 1984.

${ }^{6}$ Rising, Jerry J., Development of a Reduced Area Horizontal Tail for a Wide Body Jet Aircraft, NASA CR172278, 1984.
${ }^{7}$ Advanced Fighter Technology Integration F-111 Mission Adaptive Wing (ITAR), NASA CP-3055, 1990.

${ }^{8}$ Phillips, Paul W. and Stephen B. Smith, AFTl/F-1II Mission Adaptive Wing (MAW) Automatic Flight Control System Modes Lifi and Drag Characteristics, AFFTCTR-89-03, May 1989. (Distribution limited to U.S. Government agencies only (Test and Evaluation), Apr. 1989. Other requests for this document shall be referred to the AFTI/F-111 (MAW) Program Office (WRDC/FIMF), Wright-Patterson AFB OH 454336503.)

${ }^{9}$ Friend, Edward L., Flight Buffet Characteristics of a Smooth Variable-Camber Mission Adaptive Wing for Selected Wing Flap Deflections (ITAR), NASA TM-4455, 1993.

${ }^{10}$ Thomas, Jürgen K.W., Advanced Technology - The Key to European Competitiveness, Lecture presented to the Aeronautical Society of South Africa, Apr. 25, 1984.

${ }^{11}$ Drachenberg, H., "Weight and Center of Gravity Determination on Ground and Airborne," 45th Annual Conference of the Society of Allied Weight Engineers, Inc., Williamsburg, Virginia, SAWE paper no. 1695 , May 1986.

${ }^{12}$ Huber, Bernard, "Center of Gravity Control on Airbus Aircraft Fuel, Range and Loading Benefits," 47th Annual Conference of the Society of Allied Weight Engineers, Inc., Plymouth, Michigan, SAWE paper no. 1843, May 1988.

${ }^{13}$ Horst, Dieter, "Sideslip Indication System as a Fuel Saving Aid in Jet Transport Aircraft Operation," Proceedings of the 11th Symposium on Aircraft Integrated Data Systems, Sept. 1981, pp. 247-275.

${ }^{14}$ Szodruch, J. and R. Hilbig, "Variable Wing Camber for Transport Aircraft," Progress In Aerospace Sciences, vol. 25 , no. 3, 1988, pp. 297-328.

${ }^{15}$ Renken, J.H., "Mission-Adaptive Wing Camber Control Systems for Transport Aircraft," AIAA 85-5006, Oct. 1985.

${ }^{16}$ Renken, Jürgen, Variable Wing Camber Control Systems for the Future Airbus Program, Messerschmitt-BölkowBlohm GmbH UT-104-88, Feb. 1988 [in German; English summary].

${ }^{17}$ Spillman, J.J., "The Use of Variable Camber to Reduce Drag, Weight and Costs of Transport Aircraft," Aeronautical Journal, vol. 96, Jan. 1992, pp. 1-9. 
${ }^{18}$ Norris, Guy, "New MD-11 Update Revealed," Flight International, Dec. 21, 1994-Jan. 3, 1995, pp. 9.

${ }^{19}$ Sorensen, John A., Morello, S.A., and Erzberger, H., "Application of Trajectory Optimization Principles to Minimize Aircraft Operating Costs," Proceedings 18th Conference on Decision and Control and Symposium on Adaptive Processes, Fort Lauderdale, Florida, Dec. 12-14, 1979, pp. 415-421.

${ }^{20}$ Lee, Homer Q. and Erzberger, Heinz, Algorithm for Fixed-Range Optimal Trajectories, NASA TP-1565, 1980.

${ }^{21}$ Erzberger, Heinz, Automation of On-Board Flightpath Management, NASA TM-84212, 1981.

${ }^{22}$ Visser, H.G., An Approach to On-Board Optimization of Cruise at Constant Altitude, Delft Technische University, The Netherlands, report number LR-581, 1989.

${ }^{23}$ Gilyard, Glenn B. and Martín D. España, On the Use of Controls for Subsonic Transport Performance Improvement: Overview and Future Directions, NASA TM-4605, 1994.

${ }^{24}$ Draper, C.S. and Y.T. Li, Principles of Optimalizing Control Systems and an Application to the Internal Combustion Engine, sponsored by the Aeronautical Engineering Department, Massachusetts Institute of Technology, published by the ASME, Sep. 1951.

${ }^{25}$ Vasu, George, "Experiments with Optimalizing Controls Applied to Rapid Control of Engine Pressures with High-Amplitude Noise Signals," Transactions of the ASE, Apr. 1957, pp. 481-488.

${ }^{26}$ España, Martín and Glenn Gilyard, Direct Adaptive Performance Optimization of Subsonic Transports: A Periodic Perturbation Technique, NASA TM-4676, 1995.

27"New Large Aircraft: Big Problems," Flight International, Nov. 24-30, 1993, pp. 34-36.
${ }^{28}$ Olson, Wayne, M. and Yvonne L. Sell, "Fighter Aircraft Dynamic Performance," Proceedings of the Fourteenth Annual Symposium Society of Flight Test Engineers, Lancaster, California, Aug. 15-19, 1983, pp. 4.5-1 to 4.5-7.

${ }^{29}$ Gilyard, Glenn B. and John S. Orme, Performance Seeking Control: Program Overview and Future Directions, NASA TM-4531, 1993.

${ }^{30}$ España, Martín D. and Glenn B. Gilyard, On the Estimation Algorithm Used in Adaptive Performance Optimization of Turbofan Engines, NASA TM-4551, 1993.

${ }^{31}$ Gilyard, Glenn B., Joseph L. Conley, Jeanette Le, and Frank W. Burcham, Jr., A Simulation Evaluation of a Four-Engine Jet Transport Using Engine Thrust Modulation for Flightpath Control, NASA TM-4324, 1991.

${ }^{32}$ Iliff, Kenneth W., Maximum Likelihood Estimates of Lift and Drag Characteristics Obtained from Dynamic Aircraft Maneuvers, Proceedings, Atmospheric Flight Mechanics Conference, Arlington, Texas, Jun. 7-9, 1976, pp. 137-150.

${ }^{33}$ Rhodes, J.A., K. Ravindra, and D.M. Freidman, "CFD Drag Predictions for a Wide Body Transport Fuselage with Flight Test Verification," AIAA 93-3418, 1993.

${ }^{34}$ Weisenseel, Charles W. and Chester Gong, C-17A Cruise Configuration Performance Evaluation, AFFTC-TR-93-23, Dec. 1993. (Distribution limited to U.S. Government agencies and their contractors (Critical Technology), Sept. 1993. Other requests for this document shall be referred to ASC/YC, 2600 Paramount Place, Fairborn, Ohio 45324-6766.)

${ }^{35}$ Jackson, Michael and Dale F. Enns, A Concept for Adaptive Performance Optimization on Commercial Transport Aircraft, NASA CR-186034, 1995. 
Public reporting burden for this collection of information is estimated to average 1 hour per response, including the time for reviewing instructions, searching existing data sources, gathering and maintaining the data needed, and completing and reviewing the collection of information. Send comments regarding this burden estimate or any other aspect of this collection of information, including suggestions for reducing this burden, to Washington Headquarters Services. Directorate for Information Operations and Peports, 1215 Jefferson
Davis Highway, Sune 1204, Artington, VA 22202-4302, and to the Office of Managernent and Budget, Paperwork Reduction Project (0704-0188), Washington, DC 20503.

\begin{tabular}{|l|l|l|}
\hline 1. AGENCY USE ONLY (Leave blank) & $\begin{array}{c}\text { 2. REPORT DATE } \\
\text { January } 1996\end{array}$ & $\begin{array}{l}\text { 3. REPORT TYPE AND DATES COVERED } \\
\text { Technical Memorandum }\end{array}$ \\
\hline
\end{tabular}

\section{TITLE AND SUBTITLE}

Development of a Real-Time Transport Performance Optimization Methodology

\section{AUTHOR(S)}

Glenn Gilyard

7. PERFORMING ORGANIZATION NAME(S) AND ADDRESS(ES)

NASA Dryden Flight Research Center

P.O. Box 273

Edwards, California 93523-0273

9. SPONSORING/MONOTORING AGENCY NAME(S) AND ADDRESS(ES)

National Aeronautics and Space Administration

Washington, DC 20546-0001
5. FUNDING NUMBERS

WU 505-64-1024

\section{PERFORMING ORGANIZATION}

REPORT NUMBER

H-2085

10. SPONSORINGMONITOAING AGENCY REPORT NUMBER

NASA TM-4730

\section{SUPPLEMENTAFY NOTES}

Presented as AIAA 96-0093 at the 34th AIAA Aerospace Sciences Meeting and Exhibit,

Reno, Nevada, January 15-18, 1996.

12a. DISTRIBUTIONAVAILABILITY STATEMENT

12b. DISTRIBUTION CODE

Unclassified-Unlimited

Subject Categories 01,02 and 03

13. ABSTRACT (Maximum 200 words)

The practical application of real-time performance optimization is addressed (using a wide-body transport simulation) based on real-time measurements and calculation of incremental drag from forced response maneuvers. Various controller combinations can be envisioned although this study used symmetric outboard aileron and stabilizer. The approach is based on navigation instrumentation and other measurements found on state-of-the-art transports. This information is used to calculate winds and angle of attack. Thrust is estimated from a representative engine model as a function of measured variables. The lift and drag equations are then used to calculate lift and drag coefficients. An expression for drag coefficient, which is a function of parasite drag, induced drag, and aileron drag, is solved from forced excitation response data. Estimates of the parasite drag, curvature of the aileron drag variation, and minimum drag aileron position are produced. Minimum drag is then obtained by repositioning the symmetric aileron. Simulation results are also presented which evaluate the affects of measurement bias and resolution.

14. SUBJECT TERMS

Aircraft performance; Airfoil and wing aerodynamics; Cambered wings; Drag reduction; Fuel consumption; Flight optimization; F-111 aircraft; Optimal control; Optimization

\section{NUMBER OF PAGES}

19

16. PRICE CODE

\section{$\mathrm{AO} 3$}

20. LIMTATION OF ABSTRACT

\begin{tabular}{l|l}
\hline SECURITY CLASSIFICATION & $\begin{array}{l}\text { 19. SECURTY CLASS } \\
\text { OF ABSTRACT } \\
\text { OF THIS PAGE }\end{array}$ \\
Unclassified & Unclassified
\end{tabular}

Unlimited

Standard Form 298 (Rev. 2-89) Proeccribed by ANSI Std. Z39-19 298-102 

National Aeronautics and

Space Administration

Code JTT

Washington, D.C.

SPECIAL FOURTH-CLASS RATE POSTAGE AND FEES PAID NASA

PERMIT No. G27

\section{6-0001}

Otficial Business

Penalty for Private Use, $\$ 300$

POSTMASTER: If Undeliverable (Section 158

Postal Manual) Do Not Return 